\title{
Heteromação e microtrabalho no Brasil
}

\author{
Matheus Viana Braz* (1)
}

\section{Resumo}

No paradigma da heteromação do trabalho, as mudanças operadas pela informatização da economia fazem com que uma massa expressiva de trabalhadores passe a desempenhar atividades essenciais, mas marginais. Objetiva-se, neste estudo, analisar as diferentes formas de microtrabalho heteromatizado remunerado presentes em território nacional, de maneira a lançar luzes compreensivas sobre as condições e especificidades do contexto laboral brasileiro. Para tanto, primeiro foi realizado um levantamento e descrição dos crowdworks de microtarefas em operação no Brasil. Depois, a partir do método netnográfico nos inserimos em 22 grupos de Facebook e de Whatsapp voltados a esse mercado (o que totaliza uma base de cerca de 16 mil perfis registrados) e os acompanhamos durante sete meses. Conclui-se que, no Brasil, há uma importante reserva de mão de obra de microtrabalho e que não estamos diante de um cenário isolado, monolítico e homogêneo. O microtrabalho está imbricado em novas formas de extração de valor da plataformização do trabalho e deve ser compreendido em meio a cadeias de produção mais amplas, globais, onde as condições de trabalho são polissêmicas, assimétricas e regidas mormente por países do Norte global. ${ }^{\ominus}$

Palavras-chave: heteromação, plataformização do trabalho, microtrabalho, trabalho por peça.

\footnotetext{
* Universidade do Estado de Minas Gerais, Divinópolis, MG, Brasil.

$\checkmark$ Agradeço aos estudantes e pesquisadores vinculados ao Laboratório de Trabalho, Saúde e Processos de Subjetivação (LATRAPS/UEMG), cujas contribuições foram determinantes na construção desta pesquisa.
} 


\section{Heteromation and micro-work in Brazil}

\section{Abstract}

In the heteromation paradigm of work, the changes brought about by the computerization of the economy lead to a significant mass of workers performing essential but marginal activities. The objective of this study is to analyze the different forms of heteromatized remunerated microwork available in the national territory, in order to clarify the conditions and specificities of the Brazilian labor context. To do so, first a survey and description of microtask crowdworks in operation in Brazil was carried out. Then, using the netnographic method, we joined 22 Facebook and WhatsApp groups focused on this market (which totaled a base of around 16 thousand registered profiles) and followed them for seven months. Findings suggest that Brazil has an important part of the world's reserve of micro-work labor and that we are not facing an isolated, monolithic and homogeneous scenario. Micro-work is imbricated in new ways of extracting value from the platformization of work and must be understood in the midst of global production chains, where working conditions are polysemic, asymmetric and mainly governed by global North countries.

Keywords: heteromation, platformization of labor, micro-work, piece work.

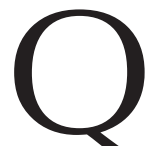

uando nos referimos à produção da Inteligência Artificial (IA), em geral associamos a esse processo trabalhos realizados por engenheiros, cientistas de dados e demais profissionais com graus elevados de especialização. Parece ainda ser pouco difundido, contudo, que em níveis elementares a preparação da IA envolve uma multidão de trabalhadores precários, dispersos em variadas geografias do mundo, que utilizam seus próprios celulares, computadores ou notebooks para realizarem, em suas casas, tarefas de baixa complexidade, cuja finalidade é executar microtrabalhos que humanos fazem de forma mais eficiente que as máquinas (Gray; Suri, 2019; Tubaro; Casilli; Coville, 2020). 
Embora alguns entusiastas aleguem que esse tipo de trabalho desaparecerá quando as tecnologias atingirem seus estágios de maturidade, endossamos a tese que rejeita a pressuposição de que o microtrabalho seria um elemento conjuntural da produção de "tecnologias inteligentes" (Ekbia; Nardi, 2017; Casilli, 2019). Como argumento de fundo desta pesquisa, defendemos a predominância do paradigma da heteromação (heteromation paradigm) (Ekbia; Nardi, 2017), de modo que as mudanças operadas pela informatização da economia fazem com que uma massa expressiva de trabalhadores passe a desempenhar atividades essenciais, mas marginais. Nessa acepção, concebe-se que tarefas elementares da cadeia produtiva da tecnologia sempre serão direcionadas a seres humanos.

Neste estudo, a exploração da noção de heteromação do trabalho tem como espinha dorsal o mercado de microtarefas. Objetiva-se analisar as diferentes formas de microtrabalho heteromatizado remunerado presentes em território nacional, de maneira a lançar luzes compreensivas sobre as condições e especificidades do contexto laboral brasileiro. Para tanto, primeiro foi feita uma conceituação sobre o paradigma da heteromação e sua relação com o trabalho digital, seguida de uma apresentação do que é o microtrabalho. Depois, discorremos acerca do delineamento metodológico da pesquisa empírica realizada, o que nos garantiu substrato suficiente para mapearmos as principais plataformas em funcionamento no Brasil e para problematizarmos algumas condições, características e especificidades desse mercado em território nacional, considerando as diferentes formas de trabalho heteromatizado.

Embora se trate de um fenômeno crescente em âmbito global, os estudos sobre o microtrabalho são recentes e surgiram em meados de 2010 (Ipeirotis, 2010). A maior parte das pesquisas se concentram, atualmente, em países da Europa e da América do Norte (Casilli, 2019), ainda que alguns trabalhos versem sobre os fluxos internacionais dos mercados desde o Sul global (Graham; Hjorth; Lehdonvirta, 2017). Não há ainda nenhuma investigação que permita situar de maneira panorâmica a oferta de microtrabalho em nosso país. 


\section{Heteromação e trabalho digital}

Sobretudo nos países desenvolvidos e emergentes, após a década de 1980 a globalização do comércio, dos produtos e das finanças consolidouse atrelada à universalização das redes eletrônicas e de comunicação (Antunes, 2018; Viana Braz, 2019, 2021). O desenvolvimento tecnológico e a intensificação da precarização se revelaram determinantes na estruturação do mercado de trabalho (Tubaro; Casilli; Coville, 2020; Viana Braz, 2021) e a informalidade se impôs como síntese ordenadora dos modos de sociabilidade relacionados ao trabalho e emprego no mundo (Antunes, 2018). No bojo da discussão sobre o desenvolvimento da IA e sua relação com o trabalho humano, há uma vasta literatura focada na automação e suas possíveis repercussões no âmbito da diminuição dos empregos (Chui; Manyika; Miremadi, 2015; Frey; Osborne, 2017; Acemoglu; Restrepo, 2018). Se essas pesquisas se endereçam à criação de hipóteses e modelos prospectivos sobre o fim dos empregos formais ou mesmo do trabalho (Rifkin, 2014), parecem ignorar o processo de produção e sustentação das "tecnologias inteligentes", assim como simplificam o processo histórico de complementariedade (e não substituição) entre o ser humano e as máquinas (Autor, 2015; Bessen, 2017; Casilli, 2019), descartando inclusive o fenômeno do aumento do hiato entre mão de obra qualificada e não-qualificada (Rodrik, 2011; Autor; Dorn, 2013; Viana Braz, 2019).

Nesse cenário, é possível conceber dois paradigmas. No primeiro, o paradigma da automação, as máquinas criariam valor por si mesmas e os sistemas automatizados aliviariam o trabalho dos humanos, mediante sua substituição (Ekbia; Nardi, 2017). No segundo, o paradigma da heteromação, as tecnologias não estariam substituindo totalmente o trabalho humano, mas o reconfigurando na forma de trabalho heteromatizado. Neste estudo, a partir da análise do microtrabalho em território brasileiro, compreendemos ser um equívoco afirmar que, ao se automatizar um trabalho humano, ele irá desaparecer (Ekbia; Nardi, 2017; Casilli, 2019). Pode ser que o emprego formal deixe de existir, mas os processos tendem a ser fragmentados, 
externalizados e produzem um deslocamento do trabalho para as margens, pois comumente são informatizados e/ou plataformizados, na forma de trabalho digital, isto é, de um trabalho taskificado (concebido como serviço) e datificado (Grohmann, 2020) que serve para desenvolver ou sustentar sistemas automáticos (Casilli, 2019).

Tecnologias concebidas como autônomas e inteligentes demandam intenso trabalho humano para cumprirem suas funções e para serem operadas com eficácia (Casilli, 2019; Gray; Suri, 2019). Tratamos, portanto, de atividades ocultadas (Gray; Suri, 2019), engendradas na informalidade, mal remuneradas ou que passam a ser naturalizadas como parte da função de "ser usuário" das tecnologias digitais. Dito de outra forma, a heteromação do trabalho traduz um processo sutil e crescente de extração de valor econômico mediante exploração da força de trabalho gratuita ou de baixo custo, em redes mediadas por tecnologias (Ekbia; Nardi, 2017; Casilli, 2019).

A título de ilustração, certamente os leitores já se depararam em algum momento com a funcionalidade reCAPTCHA, navegando na internet. Tal funcionalidade corresponde a um sistema de caixa de diálogo desenvolvido na Universidade Carnegie Mellon, adquirida há anos pela Google e utilizada no processo de digitalização de livros (Google Books) e no aperfeiçoamento de algoritmos de reconhecimento de imagens (Casilli, 2019). Ao "comprovar" que não somos um robô, identificando letras distorcidas exibidas na tela, fazemos gratuitamente microtrabalhos para a empresa. Este seria um exemplo de trabalho heteromatizado que fazemos sem nenhuma recompensa financeira, porém, conforme será explorado adiante, há diferentes tipos de heteromação também presentes em nosso cotidiano.

O trabalho heteromatizado não se contrapõe nem substitui as formas de extração de valor analisadas por Marx, em sua teorização sobre o trabalho assalariado. Refere-se somente a um mecanismo de criação de valor do capitalismo atual, o qual tende a encerrar as pessoas em plataformas e sistemas específicos, por meio de métodos de obtenção da atenção, engajamento e incitação ao trabalho não pago ou mal remunerado (Ekbia; Nardi, 2017). 
A heteromação permeia várias atividades humanas, nas mídias sociais e plataformas globais, bem como é propulsora do desenvolvimento de software, design social, tecnologias de autoatendimento de bancos, pesquisas etc (Ekbia; Nardi, 2017). Nesta investigação concentramo-nos sobre as formas de heteromação remuneradas vinculadas ao microtrabalho. Referimo-nos a uma dinâmica particular de acumulação de riquezas e geração de valor no âmbito do trabalho plataformizado. Algumas dessas atividades estão ligadas à produção, preparação e sustentação da inteligência artificial, mas outras se inserem no campo da imitação dessas tecnologias (Ekbia; Nardi, 2017; Tubaro; Casilli; Coville, 2020). Ainda que as companhias vinculadas a essas redes não tragam tal discussão e atividades à esfera pública, esse valor representa para elas um diferencial competitivo de mercado (Woodcock; Graham, 2019; Woodcock, 2021).

\section{O que é o microtrabalho?}

$\mathrm{Na}$ atualidade, organizações globais como Amazon, Microsoft, Uber, Facebook, Google, Tesla (assim como a quase totalidade de empresas que se servem de IA e big data), dependem de atividades elementares do ser humano para a preparação de seus algoritmos de machine e/ou deep learning (Gray; Suri, 2019). O desenvolvimento dos sistemas de IA passa necessariamente pelo aprendizado de padrões, mediante análise de milhões de dados. Esse processo, que exige o trabalho humano para a realização de regressão, identificação, reconhecimento e classificação de informações, é segmentado pelas empresas em microtarefas, as quais são vendidas como microsserviços em variadas plataformas no mundo, criadas para tal finalidade (Casilli, 2019; Gray; Suri, 2019).

No microtrabalho, são executadas microtarefas de baixa complexidade, que exigem pouca qualificação e, além disso, o trabalhador não conhece quem solicitou seu serviço e frequentemente não sabe qual a finalidade da tarefa que lhe foi requisitada. Remetemo-nos a um negócio com alta margem, recorrência, baixa tributação e escalável para as plataformas, além 
de implicar baixos custos marginais de serviços (sobretudo com pessoal), pois, embora subsista relação de parassubordinação e hipossuficiência (Kalil, 2019; Casilli, 2019) no trabalho, o vínculo laboral estabelecido se opera sem nenhum tipo de regulamentação. Os trabalhadores, portanto, são pagos estritamente em função das microtarefas realizadas, não possuem margens para negociações, não usufruem de comissões e tampouco qualquer tipo de proteção social ou trabalhista.

No que toca ao cerne desta pesquisa, o microtrabalho envolve quais tipos de atividades? Para reduzir seus custos internos, empresas de tecnologia terceirizam, em plataformas específicas, microtarefas que servem para alimentar seus sistemas e treinar seus algoritmos. Remetemse, portanto, sobremaneira, a atividades de moderação de conteúdos em redes sociais, categorização e reconhecimento de imagens, análise de expressões faciais, traduções pontuais, criação de palavras-chave para textos, experimentação e teste de produtos, transcrição de áudios, digitalização de documentos, preenchimento de questionários em pesquisas acadêmicas ou de mercado, visitas de sites para geração de tráfego ou mesmo ao desenho de estruturas geométricas em mapas e geolocalizações específicas (como é o caso, por exemplo, dos datasets usados nos softwares de veículos autônomos). A cada Human Intelligence Task (HIT) finalizada e aprovada pelo requisitante, o trabalhador contabiliza em sua conta online alguns centavos de dólares ou reais, os quais variam em função da qualificação do serviço (Berg et al., 2018; Casilli, 2019).

Se as plataformas da gig economy surgiram no mundo em meados dos anos 2000 (Woodcock; Graham, 2019), frutos do crescimento da internet, o crowdsourcing pioneiro para microtarefas foi lançado por Jeff Bezzos somente em 2005 (Berg et al., 2018) e é denominado Amazon Mechanical Turk'1 (AMT ou Mturk) (Berg et al., 2018). Logo depois, no

${ }^{1}$ Esse nome foi inspirado em uma máquina de xadrez criada no século XVIII, em 1770, chamada The Turk e que fora exibida durante anos por seu criador, Wolfgang von Kempelen, como uma ferramenta provida de uma inteligência artificial a qual permitia jogar contra humanos. Após cinquenta anos de sua criação, descobriu-se que $O$ Turco era na realidade uma ilusão mecânica, pois um jogador de xadrez escondido operava a máquina em seu interior. 
mesmo ano, foram criadas a Universal Human Relevance System (UHRS) e a RaterHub, plataformas da mesma natureza, controladas respectivamente pela Microsoft e Google (Tubaro; Casilli, 2019).

Estima-se que a AMT seja uma das maiores plataformas do mundo ${ }^{2}$ voltadas para microtarefas e que existam mais de 350 crowdworks (online webbased, direcionados a microtrabalho, freelance e programação competitiva) em operação (Kässi; Lehdonvirta; Stephany, 2021), movimentando uma economia de bilhões de dólares anualmente (Berg et al., 2018). Em pesquisa recente, Kässi, Lehdonvirta e Stephany (2021) projetaram a existência, atualmente, de cerca de 163 milhões de perfis registrados em plataformas de trabalho online.

No Brasil, foram encontradas somente três pesquisas empíricas com brasileiros em plataformas de microtrabalho. Duas se restringiram à Mturk e abarcaram amostragens de 52 (Kalil, 2019) e de 149 trabalhadores (Moreschi; Pereira; Cozman, 2020). Em ambos os estudos a amostra dos trabalhadores foi composta majoritariamente por homens, solteiros, com ao menos ensino superior completo ou em curso, que estavam nas referidas plataformas por falta de trabalho em suas residências, além de trabalharem em outros crowdworks.

Na terceira investigação, Grohmann e Araújo (2021) entrevistaram 16 trabalhadores da Appen e da Lionbridge. Em síntese, observou-se que as principais vantagens percebidas no microtrabalho foram a flexibilidade (trabalhar em diferentes lugares, em diferentes horas) e o recebimento em dólar, em especial devido à desvalorização da moeda brasileira. Como desvantagens, predominou a falta de segurança e de estabilidade no trabalho, ligada à possibilidade de não-pagamento das tarefas realizadas ou de rescisão repentina dos projetos aos quais estavam vinculados os trabalhadores nas plataformas.

Nesse contexto, algumas interrogações são colocadas como espinhas dorsais deste estudo: há três pesquisas que se debruçam sobre os trabalhadores

${ }^{2}$ Há na plataforma mais de 500 mil turkers (trabalhadores) registrados (Amazon Mechanical Turk, 2018). 
brasileiros na Amazon Mechanical Turk, Appen e Lionbridge, contudo, quais são as demais plataformas utilizadas em território nacional e como elas funcionam?

Antes de avançar para o próximo tópico, é preciso fazer uma digressão. Reconhecemos na designação microtrabalho um impasse. O prefixo da palavra é derivado da noção de microtarefa, porém, ainda que se trate de uma forma de trabalho fragmentada, repetitiva e que exige amiúde baixa qualificação, tal noção parece produzir um efeito colateral de reduzir e talvez depreciar o trabalho realizado pelos sujeitos.

Todo trabalho compreende uma atividade de elaboração de sensações, emoções e de produção de significados (Dejours, 2012; Lhuilier, 2017). Logo, se toda atividade implica uma tripla elaboração (agir, sentir e significar), seria equivocado falar de "microatividade" e de "microtrabalho". Lhuilier (2017), por exemplo, ao tratar de trabalhos precários, localizados na informalidade, propõe que o trabalho eventualmente pode tomar a forma de atividade empacotada (activité emballée), por meio da qual ele se fragmenta, dissocia-se do sujeito e reduz-se a um mero funcionamento procedimental. Mesmo nesses casos, em que há esvaziamento da atividade (enquanto vetor de produção de si e da sociedade), ela ainda se faz presente e supõe um duplo trabalho de subjetivação, inscrito no registro do corpo e do social.

Não podemos desprezar que o trabalho no mercado de microtarefas demanda ações físicas específicas (teclar, clicar, arrastar etc.), representações de identidade (criação de logins, perfis, usuários, preferências e escolhas), práticas digitais (verificação de e-mails, leitura de guidelines e realização de provas para obtenção de certificações), e projetos de vida (relacionado ao tempo dedicado ao trabalho, aos destinos das retribuições financeiras etc.) (Ekbia; Nardi, 2017). Com efeito, o confronto com a atividade não se reduz ao que é prévia e normativamente determinado pelas plataformas, ultrapassa as prescrições (as guidelines) e, portanto, consolida-se mediante a experiência psíquica (e intersubjetiva) da simbolização, elementar à fabricação do laço social (Viana Braz, 2019). Por isso, a noção de microtrabalho parece um 
tanto quanto simplista e reducionista, na medida em que as atividades exigem investimento psíquico e mobilização de todo o corpo do trabalhador.

Deparamo-nos, contudo, com uma aporia. Há designações variadas na literatura para se referir a esses trabalhadores, como, por exemplo, trabalhadores do clic, proletários do clic (Casilli, 2019) e cidadãos de segunda classe (Silberman, 2015). Numa perspectiva mais ampla, eles são também inseridos no que se intitula cibertariado (Huws, 2014) ou infoproletariado (Antunes, 2018). Por outro lado, parece ter se consolidado na literatura um campo de estudos específico, notadamente delineado em torno da noção de microtrabalho. Não é o foco deste artigo esgotar essa discussão e tampouco propor alguma nova conceituação; todavia esses apontamentos se fazem necessários para a expressão de nossa posição em relação a essa terminologia. Ainda que utilizemos o termo microtrabalho, prescindiremos da referência aos sujeitos como microtrabalhadores.

\section{Método}

O presente estudo faz parte de um projeto mais amplo ${ }^{3}$, conduzido no Laboratório de Trabalho, Saúde e Processos de Subjetivação (LATRAPS), no qual se objetiva cartografar o perfil sociodemográfico dos trabalhadores brasileiros de diferentes crowdworks de microtarefas e compreender a psicodinâmica de prazer, sofrimento e reconhecimento inerente às suas atividades.

Em termos metodológicos, foi feito um mapeamento das principais plataformas de microtarefas em operação no Brasil. Depois, por meio de nossa rede de contatos e mediante buscas na internet, inserimo-nos em 22 grupos de Facebook e de Whatsapp voltados diretamente a tarefas, projetos e/ou plataformas do referido mercado, o que totaliza uma base de cerca de 16 mil perfis registrados. Durante sete meses (de maio a novembro de 2020), seguindo as recomendações éticas da Association of Internet Researchers (Franzke et al., 2020), acompanhamos diariamente as

3 Projeto aprovado pelo Comitê de Ética e Pesquisa da Universidade do Estado de Minas Gerais (UEMG), sob processo no 39821920.0.0000.5115. 
trocas de mensagens em todos os grupos, a partir do método netnográfico (Fragoso; Recuero; Amaral, 2011; Kozinets, 2014). Mediante abordagem exploratória, transversal e descritiva, servimo-nos de parte desses dados para analisar qualitativamente o mercado de microtarefas e sua intersecção com formas heteromatizadas de trabalho. Investigações quantitativas (relativas à modelização e análises semânticas) serão realizadas em trabalhos futuros.

Ao ingressar em cada um dos grupos, foi feito contato com o/a respectivo(a) administrador(a) e explicitado o objetivo da inserção do pesquisador. Este ponto é fundamental, pois os principais vínculos estabelecidos com o pesquisador se efetivaram com esses trabalhadores. Por meio de observação participante, rejeitou-se uma posição de neutralidade e buscou-se uma aproximação às vivências das pessoas, colocando em primeiro plano balizadores éticos como a manutenção de suas privacidades, a confidencialidade, bem como a preservação dos grupos e das identidades dos envolvidos (Fragoso et al., 2011). Por isso, foram priorizadas as perspectivas dos trabalhadores sobre as plataformas em que trabalham e as especificidades do contexto brasileiro.

\section{Plataformas de microtarefas no Brasil}

No levantamento realizado, foram identificadas 54 plataformas de microtrabalho (ver Quadro 1, no Apêndice) em operação no Brasil até o mês de novembro de 2020, as quais foram divididas em cinco categorias, de acordo com suas atividades. Com base no estudo de Tubaro, Ludec e Casilli (2020), verificamos também os dados de navegação referentes ao mês de junho de 2021 de algumas dessas plataformas, por meio do serviço de mensuração do SimilarWeb.com, funcionalidade que permite estimar globalmente o número de visitantes únicos mensais ${ }^{4}$ em diferentes sites e aplicativos.

1) Plataformas de microtrabalho para produção e treinamento de dados, representadas, sobretudo, por plataformas globais de IA, abarcam tarefas

\footnotetext{
${ }^{4}$ Uma vez que várias plataformas se servem de interfaces secundárias e separadas para a realização de tarefas, esse recurso se revela limitado, o que indica que os valores são subestimados.
} 
como classificação de expressões faciais, categorização de publicidades, moderação de conteúdo em redes sociais e campanhas publicitárias, categorização e reconhecimento de dados (como imagens, produtos, palavras-chave, tokens e URLs), rotulagens de pontos de interesse anatômicos (como olhos, bocas e rostos), transcrição de áudios e vídeos, tradução de textos, digitalização de documentos, resposta a enquetes, categorização de dados, segmentação de pixels ou detecção de objetos em imagens (como caixas delimitadoras) etc. É comum, nesse mercado, que o trabalhador, ao se cadastrar no site ou aplicativo das plataformas, tenha que fazer provas de certificação de idiomas, de boas práticas à execução das tarefas (conforme manuais ofertados pelas empresas) e, inclusive, de aspectos éticos dela derivados. Após sua habilitação, ele pode se candidatar a projetos ou se inscrever em tarefas específicas, encomendadas por requisitantes externos, via de regra não identificados. Cada plataforma tem procedimentos específicos de conferência e avaliação dos trabalhos realizados. As recompensas financeiras são recebidas somente depois que o requisitante aprova a tarefa, pois do contrário o trabalho não é pago.

Dentre as principais plataformas dessa categoria, os dados do SimilarWeb indicam que em junho de 2021 o Brasil foi o país com maior número de visitas individuais na Ysense (714 mil, do total de 3,22 milhões), o segundo país na Appen (542 mil, do total de 6,29 milhões), atrás dos Estados Unidos, o primeiro na Clickworker (299 mil de 1,75 milhão), o segundo na Lionbridge (260 mil de 1,95 milhão), o terceiro com mais acessos à AMT, atrás dos Estados Unidos e Índia (233 mil de 3,19 milhões), o primeiro na OneForma (139 mil de 877 mil), o quarto na Microworkers (62 mil sobre 881 mil) e o segundo na Neevo (94 mil de 721 mil).

2) Plataformas de microtrabalho para realização de pesquisas de mercado, em que os trabalhadores são pagos para responder questionários e pesquisas de mercado ou acadêmicas. Nessa categoria figuram plataformas globais, como a SurveyTime, a Toluna e a Prolific, empresas da América Latina, como a Livra (sediada em Buenos Aires e que, inclusive, remunera 
os trabalhadores com vale-compras em lojas conveniadas), ademais de plataformas brasileiras, como a QualiBest.

Esses mercados, já bastante tradicionais, parecem ter se transformado e se servem da lógica da plataformização para sua reprodução e expansão. No Brasil, em termos quantitativos, a plataforma com maior número de acessos individuais no mês de junho foi a Lifepoints (678 mil, do total de 9,48 milhões), seguida da Toluna (599 mil de 9 milhões), SurveyTime (420 mil de 2,59 milhões), QualiBest (164 mil de 167 mil) e Livra (117 mil, de um total de $721 \mathrm{mil}$ ).

3) Plataformas de microtrabalho para impulsionamento de redes sociais, também conhecidas como fazendas de cliques (click farms), cujo foco é a ampliação de engajamento mediante aumento de seguidores, curtidas e inclusão de comentários em postagens e perfis de variadas mídias sociais. A plataforma oferece a terceiros serviços de impulsionamento, gerenciamento, compra e venda de seguidores de forma "automatizada". Porém, quando surgem as solicitações quem as executa são pessoas que recebem centavos de reais a cada ação realizada, por intermédio da criação de perfis falsos nas redes.

Em termos quantitativos, uma vez que esse mercado é dominado por plataformas brasileiras, que operam no idioma português, tendemos a crer que esta é a categoria com a maior quantidade e concentração de trabalhadores ativos no Brasil. Dentre as maiores plataformas, no mês de junho de 2021, a Dizu teve 1,3 milhão de visitas individuais, seguida da GanharNolnsta (1,2 milhão), SigaSocial (276 mil), Kzom (190 mil) e Everve (67 mil).

4) Plataformas de microtrabalho para pequenos serviços de freelancing, que abarcam microsserviços de baixa complexidade, como divulgação de textos e contas em redes sociais, realização de depoimentos e avaliações para empresas e produtos, transcrições e traduções breves, gravação de áudios personalizados para Whatsapp etc. Tais organizações se derivam de plataformas de freelance como Workana, GetNinjas, WeDoLogos e se 
diferenciam pelo fato de que se centram em microtarefas. Em relação aos números de visitas individuais, no Brasil, no mês de junho, as plataformas mais utilizadas foram a Vintepila (333 mil) e a Vinteconto (83 mil).

5) Plataformas de microtrabalho para testes de usabilidade remota, em que os trabalhadores são pagos para testar novos produtos (sites, versões de software, aplicativos, jogos etc.), para levantamento de informações específicas ou identificação de falhas e erros antes de os produtos serem lançados no mercado. Algumas dessas plataformas vendem também serviços de geração de tráfego, via leitura de textos ou streaming. Os procedimentos de avaliação das tarefas e a relação com os requisitantes são homólogas às plataformas de treinamentos de dados.

Este parece ser o mercado mais pulverizado, em termos de distribuição e organização dos trabalhadores. Não são encontrados grupos sobre estas plataformas com a mesma facilidade com que se encontram aqueles voltados a treinamento de dados e ao impulsionamento de mídias sociais. No que diz respeito às visitas individuais em âmbito nacional, a plataforma mais acessada no mês de junho foi a uTest (179 mil, do total de 1,35 milhão), seguida das seguintes: TimeBucks (145 mil de 4,87 milhões), Buzzbreak (89 mil de 354 mil), UserFeel (37 mil de 260 mil), Cashzine (32 mil), ClipClaps (24 mil), UsabilityHub (13 mil), Testbirds (11 mil), Ferpection (8 mil).

Foi feita uma separação das plataformas em cinco categorias, porém as fronteiras entre elas são substancialmente difusas (ver Quadro 1, no Apêndice). Organizações como Amazon Mechanical Turk e Neevo também oferecem microtarefas direcionadas a pesquisas acadêmicas e de mercado, assim como a TimeBucks abarca microsserviços de impulsionamento de redes sociais e engajamento em sites específicos. Em termos distributivos, plataformas sediadas nos Estados Unidos foram maioria (22), seguidas de Brasil (13), Austrália (3), Alemanha (3), Inglaterra (3), Argentina (1), Bulgária (1), Grécia (1), Áustria (1), China (1), França (1), Israel (1) e Malásia (1). Não conseguimos identificar em quais cidades estão sediados três crowdworks: RapidWorkers, Kzom e BroadSocial. 
As plataformas de microtrabalho listadas variam em função de suas estruturas e finalidades. Há startups do Vale do Silício, grandes grupos de multinacionais como a Appen, Amazon Mechanical Turk e Pactera, que congregam distintos tipos de microsserviços, até plataformas geridas por uma única pessoa e direcionadas a uma só finalidade, como no caso da SigaSocial. Além disso, as plataformas de treinamento de dados concentramse majoritariamente nos Estados Unidos e as ofertas de microtrabalho são disponibilizadas no idioma inglês. Já as plataformas de fazendas de cliques são sediadas em sua maioria no Brasil e, portanto, são direcionadas a brasileiros e construídas em português.

No que concerne ao desenvolvimento de "tecnologias inteligentes", Tubaro, Casilli e Coville (2020) argumentam que parcela significativa dos microtrabalhos gravitam em torno de três funções elementares: treinamento, verificação e imitação da inteligência artificial. As duas primeiras se remetem a dois subprocessos da produção de IA: de geração e anotação de dados. Ambos fazem parte da primeira fase dessa cadeia produtiva, em que dados preliminares precisam ser achados, ordenados, adequados e treinados para serem utilizados (esse é o caso de algumas plataformas localizadas nas categorias 1, 2 e 5 deste estudo) (Gray; Suri, 2019; Tubaro; Casilli; Coville, 2020). Como o aprendizado de máquinas envolve altos custos, algumas organizações terceirizam serviços supostamente feitos de forma automatizada (Tubaro; Casilli; Coville, 2020) para seres humanos, como ocorre nas plataformas localizadas nas categorias 3 e algumas tarefas da 4 . Aqui, estamos diante de um processo de imitação, em que o trabalhador substitui um trabalho que deveria ser realizado por tecnologias inteligentes. Nesse amplo espectro de trabalhos heteromatizados há tanto empresas que vendem serviços de gestão e impulsionamento de redes sociais, como também de geração de tráfego e de assistentes de agendamentos (como o Google Duplex), em que atividades são operadas online por trabalhadores humanos (Chen; Metz, 2019). 


\section{Formas de trabalho heteromatizado e particularidades do contexto brasileiro}

Ainda que estejam distantes fisicamente e não possam conversar entre si nas plataformas, os trabalhadores encontram meios para a criação de redes de relacionamentos (Woodcock, 2021). As comunicações estabelecidas entre eles cumprem função essencial na garantia do engajamento e execução das tarefas (Irani, 2015; Wood; Lehdonvirta; Graham, 2018), operam-se mediante grupos e/ou fóruns online (como Turker Nation, Mturkcrowd, Turkopticon, TurkerHub, Mturkgrind etc.), bem como produzem movimentos coletivos de resistência e de busca por melhores condições de trabalho (Woodcock, 2021). Neste estudo, tais comunicações nos auxiliaram na compreensão das diferentes formas de heteromação no microtrabalho e das condições laborais dos trabalhadores.

Globalmente, as fazendas de cliques (click farms) são usadas em amplo leque de finalidades, como viralização de marcas, produtos, propagação de textos, vídeos e conteúdos de diferentes naturezas (inclusive de fake news) (DePillis, 2014; Clarck, 2015; Casilli, 2019). Neste artigo, tratamos precisamente daquelas focadas no impulsionamento de perfis em redes sociais ou, como designam alguns autores (Confessore et al., 2018; Lindquist, 2019), nas follower factories (fábricas de seguidores), situadas no universo digital da "economia dos likes" (like economy) (Gerlitz; Helmond 2013).

Embora a compra e venda de curtidas, seguidores, contas, comentários, entre outros, seja uma prática ilegal nas mídias sociais, no Brasil as plataformas tiram proveito de um negócio que parece estar em franca expansão (Albergotti; Kuranda, 2018; Lindquist, 2019). Ramificam-se também, nos grupos, mercados paralelos como o comércio de bots, ${ }^{5}$ de perfis falsos (variam em média entre 0,50 centavos e cinco reais), SMS e Chips de celulares (usados para desbloquear contas no Instagram) que, por sua vez,

\footnotetext{
${ }^{5}$ Os "robôs" (bots) são sistemas programáveis para desempenhar tarefas pré-determinadas, repetitivas e padronizadas, como seguir perfis e curtir fotos/publicidades em mídias sociais.
} 
produzem um círculo insidioso de heteromação. O trabalhador compra um bot, para conseguir rodar mais perfis simultaneamente, fazendo menos tarefas manuais. Todavia, quanto maior o número de contas funcionando ao mesmo tempo, maior é a frequência de bloqueios pelos algoritmos do Instagram. Para evitar tais bloqueios, as pessoas despendem também tempo "alimentando e montando" esses perfis, para que pareçam verídicos. Logo, trocam seguidores em grupos específicos para tal, incluem variadas fotos, postagens e programam-se para, de tempos em tempos, assistir a stories. Ao que parece, essas práticas diminuem o índice de bloqueios.

Para efeitos de ilustração, a plataforma GanharNolnsta paga 0,006 centavos para cada ação de "seguir" e 0,003 centavos para "curtir". Para receber 60 reais por dia, o trabalhador deveria fazer 10 mil ações de seguir ou 20 mil de curtir. Isso seria possível se o trabalhador utilizasse entre 20 e 40 contas simultaneamente. Considerando os bloqueios cada vez mais frequentes de contas e os problemas corriqueiros com os bots, atingir essa cifra diária se revela dificilmente praticável. Os trabalhadores, portanto, imitam as máquinas, porém também dependem delas. Um dos momentos em que houve problemas técnicos relacionado a um desses sistemas é representativo desta relação contraditória:

- Robo não quer abrir... mds man. Cada hr eh uma coisa pqp

- Aqui tb robo ta congelado, ñ quer abrir, ta uma merda, tem que fechar e abrir td de novo

- Na moral acho que eles pegam uns programadores no meio da rua. Né normal isso não. Tipo, sai gritando ei, c sabe programar?kkkk

- Justo agora que ta pipocano tarefa. Quando tá rolando é só bloqueio na cara e falta ação

- Aqui o bot não abre nem por reza

- Na hr que eu ia participar da festa caiu td aqui tbm. Tentei até extrair o download, pq tem vez q dá certo, mas n rolou

- Ceis vao ver, assim que voltar o bot vai secar tudo as ações kkllkk 
- Eu desencanei, abri agora 3 contas na mão e já fiz 60 centavos. Voltano o bot eu logo td denovo

- Acho que eles estão tramando alguma coisa kkkkk amanhã vai ver gente xingando que perdeu 100 contas. Até o pc foi bloqueado kkkkkkkk

- É mta maracutaia mesmo. Foda vei

Grohmann et al. (2021) mencionam que essas organizações, concebidas como parasitas, são a deep web do trabalho plataformizado. Contrariamente às plataformas globais que sustentam a IA, este tipo de heteromação se circunscreve na imitação das máquinas, como se esses trabalhadores fossem "robôs humanos". Há, nesse mercado, uma forma dual de extração de valor. O trabalho heteromatizado comunicativo (Ekbia; Nardi, 2017) se desvela à medida que esses trabalhadores, mesmo que com perfis falsos, produzem conteúdos (seguir, curtir, reagir, compartilhar, postar), os quais servem para alimentar e criar valor para os usuários e as mídias sociais. Ainda que tais atividades se configurem como práticas ilegais, os dados produzidos e extraídos servem a essas redes. Já o trabalho heteromatizado cognitivo (Ekbia; Nardi, 2017) corresponde à vertente de imitação de serviços vendidos como automatizados. Além da execução das ações encomendadas, há um vasto leque de tarefas periféricas (criar perfis, "maquiá-los", comprar e vender SMS, ativar, desativar e supervisionar os bots), que demandam um trabalho cognitivo que não pode ser executado por máquinas.

Essa miríade de processos se reflete também nas condições de trabalho vivenciadas. Nos grupos, as principais queixas observadas assentam-se sobre momentos de escassez de tarefas, sobre promessas não cumpridas e sobre os descontos efetuados em perfis bloqueados (nesses casos as ações realizadas não são remuneradas). Parece ser ponto pacífico entre os trabalhadores que as tabelas de preços difundidas pelas empresas não se traduzem em realidade. A insatisfação atinge seu auge quando os pagamentos demoram a ser efetivados ou quando há os denominados golpes das plataformas (expressões usadas pelos membros dos grupos). No mês de outubro de 
2020, por exemplo, uma das plataformas de impulsionamento relatou um problema técnico em seus algoritmos e, sob a alegação de que os pontos dos usuários estavam aumentando sem que estivessem realizando ações, de maneira arbitrária, zerou o saldo de vários trabalhadores. Apresentamos abaixo fragmentos literais de uma discussão sobre o ocorrido:

- Pqp man três dias de trampo, várias horas pra me dizerem que fudeu todo mundo...

- Eu estava pegando firme mas dps dessa eu desanimei tanto que não estou sentindo vontade de usar mais o site, hoje mesmo entrei lá por 5 min e já saí, eu posso te afirmar que na minha conta não teve acréscimo de saldo nenhum, o que tiraram foi valor de trabalho feito por mim.

- O meu saldo também sumiu vei. Eu havia ganho no decorrer da semana karaio.... Sumiu ontem do nada.

- Está tudo ok agora, mas zerou meu saldo, eu tinha 10 reais ou mais lá, vão me devolver? Não resolveram nada, conversa pra boi dormir, ainda tem tarefas de dois dias atrás que tá verificando.

- O meu ajustaram os 34 reais e depois tiraram de novo como fica agora alguém tem que resolver isso.

- Eles estão roubando nos.

- Vdd eu estou puta Poq, eu estou precisando. Eh ainda beem q eu tinha feito uma retirada antes se não ia perder tudo.

- Eu também consegui fazer uma retirada antes. Mas daí fiquei juntando o dinheiro e eles descontou tudo fiquei quase zerado sendo $q$ fiz todas as tarefas q pediu.

- É pq são safados. Bora fazer um grupo do Procon e denuncia.

- Aconselho a todos a n usar mais esse site. É perda de tempo. ESTÃO TRABALHANDO DE GRAÇA.

Nessas situações, em que a insatisfação atinge seu auge, os trabalhadores tendem a migrar para outras plataformas, mas assim que se confrontam com a falta de tarefas, acabam retornando. Ao longo dos sete meses de realização da netnografia, acompanhamos sucessivas reclamações e movimentos de 
boicote às plataformas. Todavia, parece que nenhum se concretizou de fato. Isso ocorre pois embora haja um discurso de liberdade e flexibilidade no mercado de microtarefas, há uma crescente dependência dos trabalhadores em relação ao gerenciamento algorítmico (Viana Braz, 2021).

Quanto às plataformas de microtarefas de freelancing, constata-se a dependência do microtrabalho heteromatizado criativo. Bastante presente no mercado publicitário e na esteira da casualização do trabalho (Ekbia; Nardi, 2017) - em que predomina o subemprego, o freelance, o trabalho parcial, por contrato temporário, intermitente e casual -, trata-se de uma fonte de produção de valor na qual as plataformas vendem serviços ligados à criação de produtos específicos, como desenhos, logotipos, vinhetas, folders, cardápios etc. Todos esses citados podem ser adquiridos por 20 reais nas plataformas brasileiras.

Sem custos trabalhistas, as organizações ampliam suas fatias de mercado reforçando a precarização do trabalho e a autoexploração de inúmeros profissionais, com destaque, neste caso, para os designers gráficos e editores, cujas recompensas financeiras são niveladas por baixo e equiparadas ao trabalho amador. Ademais, o microtrabalho heteromatizado comunicativo e cognitivo também se faz presente nesses espaços, pois é possível, nesses sites, comprar "1000 inscritos em seu canal de Youtube", "2000 seguidores no Instagram" ou "1000 visualizações em seu vídeo do Youtube", como pode ser visto na Vinteconto.

O microtrabalho heteromatizado cognitivo está presente em distintas etapas da cadeia produtiva da IA e da computação (plataformas das categorias 1 e 5): 1) trabalho de produção das informações; 2) trabalho de captura e codificação das informações, no formato de dados; 3 ) trabalho de formatação e organização de um conjunto de dados; 4) rotulagem e validação de dados na aprendizagem supervisionada, mediante alimentação de parâmetros específicos; 5) verificação, avaliação e testes de produtos, software e modelos etc. (Pasquinelli; Joler, 2020). Segundo Casilli (2019), essa cadeia é produtora de um triplo valor do trabalho plataformizado. O valor de 
qualificação remete-se ao fato de que, para que essas plataformas funcionem, seus algoritmos necessitam de uma qualificação e alimentação contínuas de dados. Quem cria esse valor, então, são os usuários e microtrabalhadores. O valor de monetização refere-se ao processo no qual as empresas transformam os dados criados em suas plataformas em valor monetário. Ora, o controle e gestão desses dados são o principal ativo dos crowdworks. Por fim, o valor de "automação" compreende a vertente do potencial de transformação e inovação dessas plataformas, a partir da extração de dados que subsidiam a criação de novas tecnologias.

É fato que os dados são a primeira fonte de produção de valor na indústria das "tecnologias inteligentes". Treiná-los, porém, é mais complexo do que se pode imaginar. O desenho, estrutura, formatação e edição dos dados implica um trabalho cognitivo sensível, relativo aos parâmetros técnicos dos algoritmos de aprendizagem (padrões de reconhecimento, extração e geração da arquitetura algorítmica) (Pasquinelli; Joler, 2020). $\mathrm{Na}$ indústria de reconhecimento facial, por exemplo, embora possam estar presentes em nossa sociedade imaginários que dão vida e inclusive antropomorfizam a IA, os algoritmos não pensam nem captam imagens como o faz a cognição humana. Ao contrário, eles calculam pixels, bem como cadeias numéricas de proximidade e brilho, em sistemas binários de reconhecimento (Pasquinelli; Joler, 2020). Quem faz o microtrabalho de abstração e aproximação de padrões no paradigma da heteromação são os seres humanos. Às máquinas, compete o trabalho de aprendizagem e identificação desses padrões de reconhecimento de determinado campo visual. A esse respeito, uma discussão em um grupo de trabalhadores da AMT parece representativa deste processo.

- Olá Pessoal lembra que comentei q minha noiva teve 69 rejects do Brex daquele hit de 1 cents +6 cents de bonus, adivinha o motivo: por $q$ ao inves de ela colocar " $\mathrm{N}$ " maiusculo, ela colocou " $\mathrm{n}$ " minusculo. Brincadeira né, vamos ver se vai reverter.

- é complicado, tomara que revertam. 
- é pq eles fazem isso de forma automatica, entao se ta " $\mathrm{n}$ " o código ja nao vai ser reconhecido

- Kkkk n. Ou N é a mesma coisa kkk

- então, é que quem avalia primeiro essas task é um algoritmo, dai pro código não é a mesma coisa

- Aff então dão tarefas pra humanos fazer mas esperam que façamos como robôs ...

- é vdd. Pq pra um humano $\mathrm{n}$ ou $\mathrm{N}$ é a mesma coisa

- Mas esse trampo é justamente pra treinar Robôs

- Na minha opinião tá treinando errado kkkk mas td bem né, fazer o q?

Para além dos vieses históricos e algorítmicos amplificados pelo aprendizado de máquinas (Noble, 2018), a análise do microtrabalho heteromatizado evidencia a dependência do trabalho cognitivo humano, as limitações técnicas desse processo e sua origem social. Tal constatação nos leva a corroborar a tese de que a força de trabalho do mercado de microtarefas não seria proveniente de uma demanda conjuntural e temporária, mas constitui elemento essencial e estrutural da cadeia de produção da IA (Gray; Suri, 2019). A base do machine e deep learning, portanto, sempre estará engendrada na representação de comportamentos, atividades e habilidades de indivíduos, isto é, na produção social e intersubjetiva humana (Pasquinelli; Joler, 2020).

Dado que compreendemos a função elementar dos trabalhos heteromatizados comunicativos, cognitivos e criativos em algumas das plataformas analisadas, quais seriam então suas particularidades no Brasil?

As condições de trabalho variam entre as plataformas, mas em todos os grupos acompanhados, em algum momento, foram compartilhadas queixas sobre atrasos de pagamentos, problemas técnicos ou ausência de respostas por parte das plataformas, bem como frustrações sobre as atividades ou sobre a falta de transparência relacionada às taxas fixadas e retornos obtidos. Em comunidades vinculadas a projetos predeterminados, como 
Appen e Lionbridge, predominam frustrações relacionadas à nebulosidade dos critérios utilizados para o aceite do ingresso nos projetos e ansiedades vinculadas ao medo do desligamento ou bloqueio repentino.

Como as plataformas são pautadas por excesso de prescrições (Berg et al., 2018; Gray; Suri, 2019), para conseguir realizar mais tarefas, de forma mais rápida, com maior retorno financeiro, os trabalhadores burlam as normas estabelecidas. Na plataforma Oneforma (do grupo Pactera), por exemplo, existe um projeto voltado ao treinamento de dados para reconhecimento de estruturas de formulários e de grafia humana. As tarefas implicam imprimir formulários variados e preenchêlos manualmente, segundo uma ordem delimitada, porém com dados fictícios. Para fazer parte do projeto, é necessário assinar um termo, denominado Non-Disclosure Agreement (Acordo de Não-divulgação) que, dentre outras considerações, proíbe o trabalhador de compartilhar quaisquer informações sobre os projetos e atividades realizadas nas plataformas. As sanções e punições ao descumprimento do contrato aparecem ainda em letras garrafais. Além disso, para se inscrever em cada um dos projetos, é preciso obter uma nota mínima em uma qualificação geral da plataforma e em provas específicas de idiomas. Como as tarefas que primeiro se esgotam são aquelas voltadas aos idiomas português e inglês, os trabalhadores se organizavam nos grupos para conseguir certificação em outros idiomas (como francês, alemão e italiano). Em um dos grupos, cada pessoa enviava o print screen de uma questão, e o grupo pesquisava na internet até descobrir quais as respostas corretas e compartilhava uma espécie de gabarito entre os membros. Para além do ganho relacionado à ampliação do acesso aos formulários de outros idiomas, há um movimento coletivo de impressão de singularidade no trabalho, em um cenário de heteromação massificado e prescritivo. Não à toa, em variados momentos análogos a esse, o sucesso da transgressão era seguido de memes e brincadeiras, frutos de um prazer grupal por ter vencido a tecnologia e superado uma estrutura cristalizada. 
Nessa mesma perspectiva, compartilham-se estratégias relacionadas às melhores formas de prestar contas e de sacar o dinheiro logrado por meio dos microsserviços. Em plataformas como Appen e Lionbridge são compartilhadas dicas sobre como são registradas as tarefas realizadas, visto que, no fim de cada mês, é o trabalhador quem deve declarar para a empresa a carga horária cumprida e os serviços realizados. Já na Amazon Mechanical Turk, conforme aponta pesquisa de Moreschi, Pereira e Cozman (2020), como somente os trabalhadores residentes da Índia e dos Estados Unidos eram autorizados a receber diretamente o dinheiro fruto das microtarefas em suas contas bancárias, no caso dos brasileiros, os honorários eram pagos na forma de créditos de compras no website da Amazon estadunidense. Com efeito, para fazer a remuneração chegar ao Brasil, duas principais manobras eram compartilhadas nos grupos: a transformação desses créditos em giftcards da Amazon, que, por seu turno, eram vendidos em leilões online, via de regra, por valores inferiores ao que valiam originalmente; ou a transformação dos créditos em sites de criptomoedas (em especial mediante bitcoins na Avacus), que eram então convertidos em real e resgatados via Paypal. Desde o dia 26 de outubro de 2020, contudo, a AMT anunciou uma nova opção de transferência de pagamento simplificada, a qual permite que os brasileiros depositem seus honorários em uma conta bancária virtual e os resgatem diretamente via Paypal ou Transferwise. Essa transição, que ocorre gradativamente, foi liberada primeiro às contas dos trabalhadores brasileiros com melhores qualificações (medidas pela taxa de aprovação do usuário) e, até o momento, prevalece um cenário híbrido, em que alguns já conseguem fazer as retiradas diretamente e outros seguem se servindo dos outros métodos. Enfim, no mês de novembro, percebemos um crescimento exponencial de novos membros nos grupos da AMT, o que sugere que a procura pela plataforma tenderá a aumentar ainda mais com a liberação integral da operação simplificada.

A heteromação no microtrabalho, vinculada em especial à IA, é também produto da crescente autonomia geopolítica de empresas de tecnologia, 
ancorada no extrativismo do conhecimento e na invisibilização dos trabalhadores (Pasquinelli; Joler, 2020). Além das dificuldades relacionadas aos meios de pagamentos e execução das tarefas, o microtrabalho no Brasil opera em condições assimétricas, quando comparadas ao mercado do Norte global. Por exemplo, plataformas do grupo Pactera parecem fazer a reposição de tarefas em momentos específicos, de acordo com o fuso horário da região onde estão sediadas. Logo, no projeto supracitado da Oneforma, eram frequentes relatos de trabalhadores que se programavam para acordar por volta das duas horas da manhã, quando eram inseridos novos formulários. Alguns desses relatos (colhidos em variados grupos) são representativos desse processo em que todo tempo do trabalhador passa a ser encarado como tempo potencial para o trabalho:

- Ontem começou a cair tasks de madrugada, eu tava morta de sono mas fiquei umas duas horas pra $\mathrm{n}$ perder oportunidade.

- Eu só fico acordada na madrugada quando meu bebê não quer domi, ai fico na plataforma. Tipo hoje ele foi dormi 3:40 da manhã.

- Madrugada foi puxada, tive que colocar uma garrafa de café, pra ficar até 5 hs e pouco...

- Putz eu tentei acordar mas não consegui hahaua. Não sou da madrugada. Mas vou tentar essa noite, tá acabando cada vez mais rápido.

- eu acordei as $4 \mathrm{~h}$ fiz menos de 15 [tarefas]. Meu namorado virou a madrugada fazendo e flou que rendeu bem.

- Ih, gente, One não é pra mim não. Eu não posso de madrugada...

Como já ocorre historicamente no microtrabalho, os empregadores do Norte são atraídos pela oportunidade de mão de obra de menor custo em países em desenvolvimento e não desenvolvidos. Casilli (2019) se refere a esse processo como realocação como serviço, ou seja, se no passado a terceirização de mão de obra para países periféricos envolvia ao menos uma estrutura de comércio de uma companhia multinacional, atualmente, no mercado de microtarefas, essas realocações podem ser feitas em poucas horas, com custos e riscos muito baixos, por qualquer pessoa. Nesse 
sentido, são comuns nos grupos discussões relacionadas à depreciação das tarefas realizadas por brasileiros (que costumam ser pagas com valores abaixo das atividades direcionadas a países do Norte global). Alguns relatos parecem ilustrativos:

- Cara, o foda pra gente é que só pegamo as task que sobram, que a galera nos EUA n fizeram;

- "Fique atento à comunicação durante o dia, pois trabalhamos no horário do Pacífico dos EUA"... Toda vez que abro a One e tem essa msg fico puto;

- Gente pensei aqui agora... Os horários mudaram pq é horário de verão no EUA, então só vai ter hit as $23 \mathrm{~h}$;

- Hoje é feriado nos EUA? Ta mto fraco de task;

- O problema de chegar mt brasileiro na amt é que jaja vamo ta que nem os indiano, praticamente trabalhando de graça;

- Não é só br que faz errado... os indianos msm, varias hits boas são bloqueadas pra eles... pra br ainda não chegou nesse nível, mas qlqr hr chega.

A dinâmica de pagamento, reposição das tarefas e a centralização dos fusos horários nos países-sede das plataformas também fazem com que os brasileiros tenham à disposição, sobremaneira, tarefas inferiores. Quanto mais brasileiros procuram as plataformas, mais os rendimentos tendem a cair. Na Appen, por exemplo, as pessoas mais experientes relatam que em meados de 2015 recebiam uma média de dez dólares por hora de trabalho, e era comum não haver restrições de tempo nos projetos. Hoje, paga-se uma média de três a cinco dólares para fazer as mesmas tarefas. Portanto, ao considerarmos que 32 plataformas abarcadas neste estudo provêm dos Estados Unidos ou de países europeus, constatamos que são criados, nesses mercados, canais mundiais de deslocamento da força de trabalho, mediante atividades mal pagas e ocultas, cuja função consiste em prolongar os modos de espoliação econômica por parte de países colonialistas e economias imperialistas (Casilli, 2019; Woodcock; Graham, 2019). Os compradores de tarefas, instalados sobretudo na Europa e Estados Unidos, continuam a reproduzir tensões históricas e assimetrias políticas em relação ao Sul 
global (Berg et al., 2018; Casilli, 2019; Woodcock, 2021), o que indica que a discussão sobre o microtrabalho deve sempre partir das condições concretas vivenciadas por trabalhadores de cada país.

Foram demonstrados somente alguns recortes representativos de assimetrias vivenciadas por trabalhadores brasileiros, que dizem respeito ao lugar que o Brasil ocupa na geopolítica do microtrabalho heteromatizado. Em síntese, destacam-se assimetrias relacionadas às condições de trabalho e pagamento (seja em função das dificuldades de recebimento, seja pela falta de transparência das plataformas), à distribuição de tarefas (que deriva de uma lógica global e difusa) e à desvalorização da mão de obra brasileira. Além disso, exceto em países como Indonésia e Filipinas, do sudeste asiático (Lindquist, 2019), tal como no Brasil não foi encontrada na literatura tamanha presença das plataformas de fazendas de cliques. Nesse âmbito, considerando diferenças em termos de idioma, parece haver distintos marcadores de classe, gênero e raça que caracterizam os trabalhadores atuantes em plataformas brasileiras e globais. Apesar dessa hipótese, o método usado não nos permite avançar nessas postulações, de maneira que se indica que trabalhos futuros possam cartografar os perfis sociodemográficos de diferentes cenários do microtrabalho no Brasil.

Por fim, apreendemos que o mercado de microtarefas constitui palco privilegiado de análise do paradigma da heteromação, pois, ainda que as microtarefas sejam simples, repetitivas e exijam amiúde baixa qualificação, não prescindem das capacidades cognitivas, criativas e intuitivas dos trabalhadores, as quais, por sua vez, são mobilizadas por incentivos econômicos (Ekbia; Nardi, 2017). Considerando a relação de anonimato e impessoalidade que blinda os requisitantes das tarefas e as plataformas, esse trabalho cognitivo é concebido tal qual um serviço encomendado e fruto de uma relação com uma máquina. É justamente por isso que Ekbia e Nardi (2017) mencionam que, no microtrabalho, os trabalhadores são tratados não somente como números, mas como software. A pessoa por detrás da tarefa realizada desaparece e as avaliações são feitas de maneira fria, tal como um processo de conferência de dados gerados automaticamente por um computador. 


\section{Considerações finais}

Neste artigo, sustentamos a premissa de que o mercado de microtarefas representa o arquétipo de formas heteromatizadas de trabalho, marcadas por algumas características elementares: (i) a radicalização da flexibilização (Antunes, 2018) faz com que trabalhadores de variadas geografias do mundo concorram entre si em tempo real, em condições notadamente assimétricas, na busca por compensações financeiras; (ii) no bojo da taskificação das atividades (Grohmann; Qiu, 2020), em que o trabalho tende a ser concebido como serviço, cresce o potencial de expansão, interconexão e mobilidade do capital financeiro que sustenta as plataformas, o que torna os trabalhadores ainda mais dispersos, descartáveis e invisibilizados; (iii) as condições, organização e relações de trabalho são cada vez mais condicionadas pela gestão algorítmica, o que altera as dinâmicas de sociabilidade e de organização coletiva dos trabalhadores (Viana Braz, 2019, 2021).

A partir das teses de Ekbia e Nardi (2017), entendemos que a heteromação do trabalho implica uma configuração sociotécnica específica (e central) de produção de valor mediante a exploração de uma força de trabalho invisibilizada e mal remunerada, na qual a inteligência e criatividade humanas são desvalorizadas e ocultadas. Dado que a heteromação no microtrabalho se desvela como um diferencial competitivo central do capitalismo hodierno e vetor de produção de valor econômico, esse mercado tende a se expandir, o que significa que veremos cada vez mais humanos trabalhando para máquinas (em atividades marginais, mas essenciais), servindo-as para torná-las mais operantes e inteligentes.

Em meio a esse cenário global de transformações no mundo do trabalho, onde estaria o Brasil na geopolítica do microtrabalho? Se nos remetermos à precarização que sustenta o mercado das tecnologias inteligentes, e considerando que, em pesquisa recente (Oxford Insights, 2020), o Brasil ficou em 63이 lugar no ranking global de estágio de preparação para IA, entendemos que estamos distantes de assumir uma posição de proeminência em termos de produção de "tecnologias inteligentes". Por outro lado, as plataformas de microtrabalho parecem se proliferar em nosso país, de maneira que 
os trabalhadores servem como mão de obra barata, invisível e temporária a crowdworks globais, que prescindem de qualquer responsabilização perante as regulações trabalhistas locais. Igualmente, constatamos que as condições de se realizar o microtrabalho são notadamente assimétricas e mais precárias, no Brasil, quando comparadas àquelas dos países do Norte global (Berg et al., 2018; Woodcock, 2021), de maneira que a exploração euro-americana (centro-periférica) ainda constitui marca preponderante da divisão internacional do trabalho, inclusive nesse mercado. Logo, se o Brasil tem potencial para assumir a dianteira de alguma das frentes da cadeia de IA, apostaríamos na proliferação das plataformas de imitação de IA (Tubaro; Casilli; Coville, 2020), tal como ocorre com o microtrabalho das fazendas de cliques. Fazemos tal afirmação (com certa dose de pessimismo), pois não encontramos o movimento dessas plataformas com tamanha força em outros países e, somente no ano de 2020, cinco negócios dessa natureza foram iniciados no país, o que sugere que, embora se trate de um fenômeno germinal, há nele um potencial de reprodução expressivo.

A análise dos tipos de plataformas em operação em território nacional e a apresentação dos números de acessos individuais aos seus sites e aplicativos nos permite pressupor que uma das principais reservas de mão de obra do microtrabalho no mundo se encontra no Brasil. Esta pesquisa contribuiu no sentido de identificar e visibilizar essas formas de trabalho, bem como de demonstrar que não estamos diante de um cenário isolado, monolítico, homogêneo, fruto de ações que têm por finalidade oferecer aos trabalhadores uma mera renda-extra. O microtrabalho, enfim, está imbricado em formas específicas de extração de valor da plataformização do trabalho e deve ser compreendido como parte de cadeias de produção mais amplas, globais, em que os mercados e as condições de trabalho são polissêmicos, assimétricos e regidos mormente por países do Norte global.

Matheus Viana Braz é Doutor em Psicologia e professor no curso de Psicologia da Universidade do Estado de Minas Gerais (UEMG) e do Programa de Pós-Graduação em Psicologia da Universidade Estadual de Maringá (UEM).

$\triangle$ matheus.braz@uemg.br 


\section{Referências}

1. ACEMOGLU, Daron; RESTREPO, Pascual. The race between man and machine: Implications of technology for growth, factor shares, and employment. American Economic Review, v. 108, n. 6, p. 1488-1542, 2018. https://doi.org/10.1257/ aer.20160696

2. ALBERGOTTI, Reed; KURANDA, Sarah. Instagram's growing bot problem. The Information, 18 jul. 2018. Disponível em: https://www.theinformation.com/ articles/instagrams-growing-bot-problem

3. AMAZON MECHANICAL TURK. Overview of mechanical turk. Publicado em 2018. Disponível em: https://www.mturk.com/help

4. ANTUNES, Ricardo. O privilégio da servidão: o novo proletariado de serviços na era digital. São Paulo: Boitempo, 2018.

5. AUTOR, David H. Why are there still so many jobs? The history and future of workplace automation. Journal of Economic Perspectives, v. 29, n. 3, p. 3-30, 2015. https://doi.org/10.1257/jep.29.3.3

6. AUTOR, David H.; DORN, David. The growth of low-skill service jobs and the polarization of the US labor market. American Economic Review, v. 103, n. 5, p. 1553-1597, 2013. https://doi.org/10.1257/aer.103.5.1553

7. BERG, Janine; FURRER, Marianne; HARMON, Ellie; RANI, Uma; SILBERMAN Six. Digital labour platforms and the future of work: towards decent work in the on-line world. Geneva: International Labour Office, 2018.

8. BESSEN, James E. Automation and jobs: When technology boosts employment. Boston University School of Law, Law and Economics Research Paper n. 07-19. Boston: Boston University School of Law, 2017. p. 1-50. Disponível em: https:// papers.ssrn.com/sol3/papers.cfm?abstract id=2935003

9. CASILLI, Antonio. En attendant les robots : enquête sur le travail du clic. Paris: Seuil, 2019.

10. CASILLI, Antonio; TUBARO, Paola; LE LUDEC, Clément; COVILLE, Marion; BESENVAL, Maxime; MOUHTARE, Touhfat; WAHAL, Elinor. Le Micro-travail en France. Derrière l'automatisation de nouvelles précarités au travail ? Rapport Final Projet DiPLab. Paris: Institut de Recherches Economiques et Sociales (IRES), 2019.

11. CHEN, Brian; METZ, Cade. Google's Duplex uses A.I. to mimic humans (sometimes). The New York Times, 22 maio 2019. Disponível em: https://www. nytimes.com/2019/05/22/technology/personaltech/ai-google-duplex.html

12. CHUI, Michael; MANYIKA, James; MIREMADI, Mehdi. Four fundamentals of workplace automation. McKinsey Digital, 1 nov. 2015. Disponível em: https://www.mckinsey.com/business-functions/mckinsey-digital/our-insights/fourfundamentals-of-workplace-automation\#

13. CLARCK, Doug B. The bot bubble: how click farms have inflated social media currency. The New Republic, 21 abr. 2015. Disponível em: https://newrepublic. com/article/121551/bot-bubble-click-farms-have-inflated-social-media-currency 
14. CONFESSORE, Nicholas; DANCE, Gabriel J. X.; HARRIS, Richard; HANSEN, Mark. The follower factory. Everyone wants to be popular online. Some even pay for it. Inside social media's black market. The New York Times, 27 jan. 2018. Disponível em:https:/www.nytimes.com/interactive/2018/01/27/technology/ social-media-bots.html

15. DEJOURS, Christophe. Trabalho vivo: trabalho e emancipação. (Tradução de Frank Sudant). Brasília: Paralelo 15, 2012.

16. DEPILLIS, Lydia. Click farms are the new sweatshops. The Washington Post, 6 jan. 2014. Disponível em: https://www.washingtonpost.com/news/wonk/ wp/2014/01/06/click-farms-are-the-new-sweatshops/

17. EKBIA, Hamid R.; NARDI, Bonnie. Heteromation, and other stories of computing and capitalism. Cambridge: MIT Press, 2017.

18. FRAGOSO, Suely; RECUERO, Raquel; AMARAL, Adriana. Métodos de pesquisa para internet. Porto Alegre: Sulina, 2011.

19. FRANZKE, Aline S.; BECHMANN, Anja; ZIMMER, Michael; ESS, Charles. Internet research: ethical guidelines 3.0. Association of Internet Researchers. Disponível em: https://aoir.org/reports/ethics3.pdf

20. FREY, Carl B.; OSBORNE, Michael A. The future of employment: How susceptible are jobs to computerization? Technological Forecasting and Social Change, v. 114, n. 1, p. 254-280, 2017. https://doi.org/10.1016/j. techfore.2016.08.019

21. GERLITZ, Carolin; HELMOND, Anne. The like economy: Social buttons and the data-intensive web. New Media \& Society, v. 15, n. 8, p. 1348-1365, 2013. https://doi.org/10.1177/1461444812472322

22. GRAHAM, Mark; HJORTH, Isis; LEHDONVIRTA, Vili. Digital labour and development: impacts of global digital labour platforms and the gig economy on worker livelihoods. Transfer - European Review of Labour and Research, v. 23, n. 2, p. 135-162, 2017. https://doi.org/10.1177\%2F1024258916687250

23. GRAY, Mary L.; SURI, Siddharth. Ghost work: How to stop Silicon Valley from building a new global underclass. Boston: Houghton Mifflin Harcourt, 2019.

24. GROHMANN, Rafael. Plataformização do trabalho: entre dataficação, financeirização e racionalidade neoliberal. Revista Eletrônica Internacional de Economia Política da Informação, da Comunicação e da Cultura, v. 22, n. 1, p. 106-122, 2020.

25. GROHMANN, Rafael; ARAÚJO, Willian F. Beyond Mechanical Turk: the work of Brazilians on global AI platforms. In: VERDEGEM, Pieter. AI for everyone? Critical perspectives. London: University of Westminster Press, 2021. p. 247-266.

26. GROHMANN, Rafael; QIU, Jack. Contextualizando o trabalho em plataformas. Contracampo: Brazilian Journal of Communication, v. 39, n. 1, p. 107-122, 2020. https://doi.org/10.22409/contracampo.v39i1.42260 
27. GROHMANN, Rafael; SOARES, Alison; MATOS, Évelin; AQUINO, Maria Clara; AMARAL, Adriana; GOVARI, Caroline. O que são as plataformas de fazendas de cliques e por que elas importam. Nexo Políticas Públicas. 06 de maio de 2021. Disponível em: https://pp.nexojornal.com.br/ponto-de-vista/2021/ O-que-s\%C3\%A3o-plataformas-de-fazendas-de-clique-e-por-que-elas-importam

28. HUWS, Ursula. Labor in the global digital economy: the cybertariat comes of age. Nova York: New York University, 2014.

29. IPEIROTIS, Panagiotis G. Demographics of Mechanical Turk. NYU Working Paper No. CEDER-10-01, março, 2010. Disponível em: https://papers.ssrn.com/ sol3/papers.cfm?abstract id $=1585030$

30. IRANI, Lilly. The cultural work of microwork. New Media \& Society, v. 17, n. 5, p. 720-739, 2015. https://doi.org/10.1177/1461444813511926

31. KALIL, Renan B. Capitalismo de plataforma e Direito do Trabalho: crowdwork e trabalho sob demanda por meio de aplicativos, 366f. Tese (Doutorado em Direito) - Programa de Pós-Graduação em Direito, Direito do Trabalho e da Seguridade Social, Universidade de São Paulo, 2019.

32. KÄSSI, Otto; LEHDONVIRTA, Vili; STEPHANY, Fabian. How many online workers are there in the world? A data-driven assessment. Social Science Research Network, 23 mar. 2021. http://dx.doi.org/10.2139/ssrn.3810843

33. LHUILIER, Dominique. O agir em psicossociologia do trabalho. Psicologia em Revista, v. 23, n. 1, p. 295-311, 2017. https://doi.org/10.5752/P.16789563.2017v23n1p295-311

34. LINDQUIST, Johan. Illicit Economies of the internet: click farming in Indonesia and beyond. Made in China, 12 jan. 2019. Disponível em: https:// madeinchinajournal.com/2019/01/12/illicit-economies-of-the-internet-clickfarming-in-indonesia-and-beyond/

35. MORESCHI, Bruno; PEREIRA, Gabriel; COZMAN, Fabio G. The Brazilian workers in Amazon Mechanical Turk: dreams and realities of ghost workers. Contracampo: Brazilian Journal of Communication, v. 39, n. 1, p. 44-64, 2020. https://doi.org/10.22409/contracampo.v39i1.38252

36. NOBLE, Safiya U. Algorithms of oppression: how search engines reinforce racism. Nova York: NYU Press, 2018.

37. OXFORDINSIGHTS. Al readiness index 2020. Oxford Insights, 2020. Disponível em: https://www.oxfordinsights.com/government-ai-readiness-index-2020

38. PASQUINELLI, Matteo; JOLER, Vladan. The Nooscope manifested: Al as instrument of knowledge extractivism. Al \& Society. 21 de novembro de 2020. https://doi.org/10.1007/s00146-020-01097-6

39. RIFKIN, Jeremy. La nouvelle société du coût marginal zéro : I'internet des objets, l'émergence des communaux collaboratifs et l'éclipse du capitalisme. Paris: Editions Les Liens qui Libèrent, 2014. 
40. RODRIK, Dani. A globalização foi longe demais? São Paulo: Editora Unesp, 2011.

41. SILBERMAN, Six M. Human-centered computing and the future of work: lessons from Mechanical Turk and Turkopticon. Tese (Doutorado em Filosofia), University of California, Irvine, 2015. Disponível em: https://escholarship.org/uc/ item/1s32t9n3

42. TUBARO, Paola; CASILLI, Antonio. Micro-work, artificial intelligence and the automotive industry. Journal of Industrial and Business Economics, n. 46, p. 333-345, 2019. https://doi.org/10.1007/s40812-019-00121-1

43. TUBARO, Paola; CASILLI, Antonio; COVILLE, Marion. The trainer, the verifier, the imitator: three ways in which human platform workers support artificial intelligence. Big Data \& Society. p. 1-12, 24 de abril de 2020. https://doi. org/10.1177/2053951720919776

44. TUBARO, Paola; LUDEC, Clément; CASILLI, Antonio A. Counting 'microworkers': societal and methodological challenges around new forms of labour. Work Organization, Labour \& Globalization, v. 14, n.1, p. 67-82, 2020. https:// doi.org/10.13169/workorgalaboglob.14.1.0067

45. VIANA BRAZ, Matheus. Paradoxos do trabalho: as faces da insegurança, da performance e da competição. Curitiba: Appris, 2019.

46. VIANA BRAZ, Matheus. Trabalho, sociologia clínica e ação: alternativas à individualização do sofrimento. Porto Alegre: Editora Fi, 2021.

47. WOOD, Alex; LEHDONVIRTA, Vili; GRAHAM, Mark. Workers of the Internet unite? Online freelancer organisation among remote gig economy workers in six Asian and African countries. New Technology, Work and Employment, v. 33, n. 2, p. 95-112, 2018. https://doi.org/10.1111/ntwe.12112

48. WOODCOCK, Jamie; GRAHAM, Mark. The gig economy: a critical introduction. Cambridge: Polity, 2019.

49. WOODCOCK, Jamie. The fight against platform capitalism: an inquiry into the global struggles of the gig economy. Londres: University of Westminster Press, 2021. https://doi.org/10.16997/book51.d

Recebido: 26 jan. 2021.

Aceito: 03 ago. 2021. 


\section{Apêndice}

Quadro 1. Plataformas de microtrabalho em operação no Brasil

Microtarefas de produção e treinamento de dados

Microtarefas de pesquisas de mercado

Microtarefas de impulsionamento de redes sociais

Microtarefas de freelancing

Microtarefas de testes de usabilidade remota

\begin{tabular}{|c|c|c|c|c|c|}
\hline & $\begin{array}{l}\text { Nome da } \\
\text { Plataforma }\end{array}$ & $\begin{array}{l}\text { Atividades } \\
\text { on-line }\end{array}$ & $\begin{array}{l}\text { Data de } \\
\text { Criação }\end{array}$ & Sede & Observações \\
\hline 1 & ${ }^{1}$ Clickworker & $\begin{array}{l}\text { Produção e } \\
\text { treinamento de } \\
\text { dados }\end{array}$ & 2005 & $\begin{array}{c}\text { Essen } \\
\text { (Alemanha) }\end{array}$ & Acesso à UHRS (Microsoft) \\
\hline 2 & Microworkers & $\begin{array}{l}\text { Produção e } \\
\text { treinamento de } \\
\text { dados }\end{array}$ & 2009 & $\begin{array}{c}\text { Dallas (Estados } \\
\text { Unidos) }\end{array}$ & \\
\hline 3 & ${ }^{1}$ Appen & $\begin{array}{l}\text { Produção e } \\
\text { treinamento de } \\
\text { dados }\end{array}$ & 1996 & $\begin{array}{l}\text { Charswood } \\
\text { (Austrália) }\end{array}$ & $\begin{array}{l}\text { Acesso à múltiplas } \\
\text { plataformas }\end{array}$ \\
\hline 4 & ${ }^{1}$ Pactera & $\begin{array}{l}\text { Produção e } \\
\text { treinamento de } \\
\text { dados }\end{array}$ & 1995 & $\begin{array}{l}\text { Pequim } \\
\text { (China) }\end{array}$ & $\begin{array}{l}\text { Acesso à UHRS (Microsoft) } \\
\text { e outras plataformas de } \\
\text { propriedade da companhia } \\
\text { (por exemplo, OneForma) }\end{array}$ \\
\hline 5 & ${ }^{1}$ Lionbridge & $\begin{array}{l}\text { Produção e } \\
\text { treinamento de } \\
\text { dados }\end{array}$ & 1996 & $\begin{array}{l}\text { Waltham } \\
\text { (Estados } \\
\text { Unidos) }\end{array}$ & $\begin{array}{l}\text { Acesso à RaterHub (Google) } \\
\text { e outras plataformas de } \\
\text { propriedade da companhia. } \\
\text { Empresa chegou a encerrar } \\
\text { temporariamente, em } 2019, \\
\text { as inscrições de brasileiros } \\
\text { microtrabalhadores, em } \\
\text { razão do excesso de procura }\end{array}$ \\
\hline 6 & ${ }^{1}$ Ysense & $\begin{array}{l}\text { Produção e } \\
\text { treinamento de } \\
\text { dados }\end{array}$ & 2007 & $\begin{array}{l}\text { Hampstead } \\
\text { (Estados } \\
\text { Unidos) }\end{array}$ & $\begin{array}{l}\text { Anteriormente denominada } \\
\text { Clixsense, garante o acesso à } \\
\text { múltiplas plataformas }\end{array}$ \\
\hline 7 & $\begin{array}{l}\text { Amazon } \\
\text { Mechanical } \\
\text { Turk }\end{array}$ & $\begin{array}{l}\text { Produção e } \\
\text { treinamento de } \\
\text { dados }\end{array}$ & 2005 & $\begin{array}{c}\text { Seattle (Estados } \\
\text { Unidos) }\end{array}$ & \\
\hline 8 & InstaGC & $\begin{array}{l}\text { Produção e } \\
\text { treinamento de } \\
\text { dados }\end{array}$ & 2011 & $\begin{array}{l}\text { Sellersburg } \\
\text { (Estados } \\
\text { Unidos) }\end{array}$ & Acesso à múltiplas plataformas \\
\hline 9 & TranscribeMe & $\begin{array}{l}\text { Produção e } \\
\text { treinamento de } \\
\text { dados }\end{array}$ & 2011 & $\begin{array}{l}\text { San Francisco } \\
\text { (Estados } \\
\text { Unidos) }\end{array}$ & \\
\hline
\end{tabular}


Continuação Quadro 1...

\begin{tabular}{|c|c|c|c|c|c|}
\hline 10 & CrowdSource & $\begin{array}{l}\text { Produção e } \\
\text { treinamento de } \\
\text { dados }\end{array}$ & 2017 & $\begin{array}{l}\text { Swansea } \\
\text { (Estados } \\
\text { Unidos) }\end{array}$ & \\
\hline 11 & Figure Eight & $\begin{array}{l}\text { Produção e } \\
\text { treinamento de } \\
\text { dados }\end{array}$ & 2007 & $\begin{array}{c}\text { San Francisco } \\
\text { (Estados } \\
\text { Unidos) }\end{array}$ & $\begin{array}{l}\text { Plataforma antes nomeada } \\
\text { CrowdFlower, teve nome } \\
\text { alterado após recompra } \\
\text { pela Appen }\end{array}$ \\
\hline 12 & Spare5 & $\begin{array}{l}\text { Produção e } \\
\text { treinamento de } \\
\text { dados }\end{array}$ & 2014 & $\begin{array}{l}\text { Seattle (Estados } \\
\text { Unidos) }\end{array}$ & $\begin{array}{l}\text { Plataforma controlada } \\
\text { pela empresa Mighty A.I., } \\
\text { adquirida pela Uber }\end{array}$ \\
\hline 13 & SequenceWork & $\begin{array}{l}\text { Produção e } \\
\text { treinamento de } \\
\text { dados }\end{array}$ & 2018 & $\begin{array}{l}\text { Birmingham } \\
\text { (Inglaterra) }\end{array}$ & \\
\hline 14 & HiveWork & $\begin{array}{l}\text { Produção e } \\
\text { treinamento de } \\
\text { dados }\end{array}$ & 2013 & $\begin{array}{c}\text { San Francisco } \\
\text { (Estados } \\
\text { Unidos) }\end{array}$ & $\begin{array}{l}\text { Em 2019, a empresa criou } \\
\text { um site em português } \\
\text { direcionado à expansão no } \\
\text { mercado brasileiro }\end{array}$ \\
\hline 15 & Crowdtask & $\begin{array}{l}\text { Produção e } \\
\text { treinamento de } \\
\text { dados }\end{array}$ & 2013 & $\begin{array}{l}\text { Belo Horizonte } \\
\text { (Brasil) }\end{array}$ & $\begin{array}{l}\text { Plataforma sob propriedade } \\
\text { da Base } 2 \text { Tecnologia, } \\
\text { fundada em } 2005\end{array}$ \\
\hline 16 & RemoTasks & $\begin{array}{l}\text { Produção e } \\
\text { treinamento de } \\
\text { dados }\end{array}$ & 2017 & $\begin{array}{c}\text { San Francisco } \\
\text { (Estados } \\
\text { Unidos) }\end{array}$ & $\begin{array}{l}\text { Foco na classificação de } \\
\text { imagens, transcrições deáudios } \\
\text { e moderações de conteúdo }\end{array}$ \\
\hline 17 & RapidWorkers & $\begin{array}{l}\text { Produção e } \\
\text { treinamento de } \\
\text { dados }\end{array}$ & 2017 & $\begin{array}{l}\text { Não } \\
\text { identificado }\end{array}$ & $\begin{array}{l}\text { Poucas tarefas disponíveis } \\
\text { para brasileiros }\end{array}$ \\
\hline 18 & Neevo & $\begin{array}{l}\text { Produção e } \\
\text { treinamento de } \\
\text { dados }\end{array}$ & 2015 & $\begin{array}{l}\text { Seattle (Estados } \\
\text { Unidos) }\end{array}$ & $\begin{array}{l}\text { Plataforma controlada pela } \\
\text { empresa DefinedCrowd, que } \\
\text { já conta com mais de } 300 \text { mil } \\
\text { microtrabalhadores registrados }\end{array}$ \\
\hline 19 & Livra & $\begin{array}{l}\text { Pesquisas de } \\
\text { mercado }\end{array}$ & 1999 & $\begin{array}{c}\text { Buenos Aires } \\
\text { (Argentina) }\end{array}$ & $\begin{array}{l}\text { Plataforma baseada em } \\
\text { respostas de pesquisas de } \\
\text { mercado, em troca de pontos } \\
\text { para aquisição de produtos } \\
\text { em empresas conveniadas }\end{array}$ \\
\hline 20 & Prolific & $\begin{array}{l}\text { Produção e } \\
\text { treinamento de } \\
\text { dados/ Pesquisas } \\
\text { de mercado }\end{array}$ & 2014 & $\begin{array}{c}\text { Oxford } \\
\text { (Inglaterra) }\end{array}$ & \\
\hline 21 & Myiyo & $\begin{array}{l}\text { Pesquisas de } \\
\text { mercado }\end{array}$ & 2010 & $\begin{array}{l}\text { Düsseldorf } \\
\text { (Alemanha) }\end{array}$ & $\begin{array}{l}\text { Plataforma baseada em respostas } \\
\text { de pesquisas de mercado }\end{array}$ \\
\hline
\end{tabular}


Continuação Quadro 1...

\begin{tabular}{|c|c|c|c|c|c|}
\hline 22 & $\begin{array}{l}\text { LifePoints } \\
\text { Brasil }\end{array}$ & $\begin{array}{l}\text { Pesquisas de } \\
\text { mercado }\end{array}$ & 2019 & $\begin{array}{l}\text { Warren } \\
\text { (Estados } \\
\text { Unidos) }\end{array}$ & $\begin{array}{l}\text { Plataforma baseada em } \\
\text { respostas de pesquisas de } \\
\text { mercado (respondidas via } \\
\text { email), em troca de pontos } \\
\text { para aquisição de produtos } \\
\text { em empresas conveniadas. } \\
\text { Antes denominada Global } \\
\text { Test Market, empresa de } \\
\text { propriedade do grupo } \\
\text { Lightspeed }\end{array}$ \\
\hline 23 & Toluna Brazil & $\begin{array}{l}\text { Pesquisas de } \\
\text { mercado }\end{array}$ & 2000 & $\begin{array}{l}\text { São Paulo } \\
\text { (Brasil) }\end{array}$ & $\begin{array}{l}\text { Plataforma baseada em } \\
\text { respostas de pesquisas de } \\
\text { mercado. Filial brasileira } \\
\text { do grupo Toluna Corporate } \\
\text { (França) }\end{array}$ \\
\hline 24 & QualiBest & $\begin{array}{l}\text { Pesquisas de } \\
\text { mercado }\end{array}$ & 2000 & $\begin{array}{l}\text { São Paulo } \\
\text { (Brasil) }\end{array}$ & $\begin{array}{l}\text { Plataforma filiada à } \\
\text { Associação Brasileira de } \\
\text { Empresas de Pesquisa e } \\
\text { baseada em respostas de } \\
\text { pesquisas de mercado, } \\
\text { em troca de pontos para } \\
\text { aquisição de produtos em } \\
\text { empresas conveniadas }\end{array}$ \\
\hline 25 & SurveyTime & $\begin{array}{l}\text { Pesquisas de } \\
\text { mercado }\end{array}$ & 2011 & $\begin{array}{l}\text { Rehovot } \\
\text { (Israel) }\end{array}$ & $\begin{array}{l}\text { A plataforma é propriedade } \\
\text { da Persona.ly, empresa } \\
\text { com escritórios nos Estados } \\
\text { Unidos, Japão, Coréia do } \\
\text { Sul, China e Israel. } \\
\text { A plataforma paga o valor } \\
\text { fixo de um dólar para cada } \\
\text { pesquisa concluída }\end{array}$ \\
\hline 26 & Pinion & $\begin{array}{l}\text { Pesquisas de } \\
\text { mercado/ } \\
\text { Microtarefas } \\
\text { localizadas }\end{array}$ & 2012 & $\begin{array}{c}\text { São Paulo } \\
\text { (Brasil) }\end{array}$ & $\begin{array}{l}\text { Pesquisas de Mercado, mas } \\
\text { que exigem geolocalização } \\
\text { específica }\end{array}$ \\
\hline 27 & 1Dizu & $\begin{array}{l}\text { Impulsionamento } \\
\text { de engajamento } \\
\text { no Instagram e } \\
\text { TikTok }\end{array}$ & 2019 & Goiânia (Brasil) & $\begin{array}{l}\text { Acesso ao Instagram } \\
\text { mediante sincronização de } \\
\text { contas }\end{array}$ \\
\hline 28 & 1SigaSocial & $\begin{array}{l}\text { Impulsionamento } \\
\text { de engajamento } \\
\text { no Instagram }\end{array}$ & 2020 & $\begin{array}{l}\text { Três de Maio } \\
\text { (Brasil) }\end{array}$ & $\begin{array}{l}\text { Acesso ao Instagram } \\
\text { mediante sincronização de } \\
\text { contas }\end{array}$ \\
\hline
\end{tabular}


Continuação Quadro 1...

\begin{tabular}{|c|c|c|c|c|c|}
\hline 29 & 1GanharNolnsta & $\begin{array}{l}\text { Impulsionamento } \\
\text { de engajamento } \\
\text { no Instagram }\end{array}$ & 2020 & $\begin{array}{l}\text { Mairinque } \\
\text { (Brasil) }\end{array}$ & $\begin{array}{l}\text { Acesso ao Instagram } \\
\text { mediante sincronização de } \\
\text { contas }\end{array}$ \\
\hline 30 & 1FarmarSocial & $\begin{array}{l}\text { Impulsionamento } \\
\text { de engajamento } \\
\text { no Instagram, } \\
\text { Facebook e } \\
\text { Youtube }\end{array}$ & 2020 & $\begin{array}{l}\text { São Paulo } \\
\text { (Brasil) }\end{array}$ & $\begin{array}{l}\text { Acesso às mídias sociais } \\
\text { mediante sincronização de } \\
\text { contas. }\end{array}$ \\
\hline 31 & 1 Kzom & $\begin{array}{l}\text { Impulsionamento } \\
\text { de engajamento } \\
\text { no Instagram }\end{array}$ & 2020 & $\begin{array}{l}\text { Cidade não } \\
\text { identificada } \\
\quad \text { (Brasil) }\end{array}$ & $\begin{array}{l}\text { Acesso às mídias sociais } \\
\text { mediante sincronização } \\
\text { de contas. Os pontos } \\
\text { obtidos podem ser } \\
\text { convertidos em dinheiro } \\
\text { ou trocados por seguidores } \\
\text { nos perfis pessoais dos } \\
\text { microtrabalhadores }\end{array}$ \\
\hline 32 & 1BroadSocial & $\begin{array}{l}\text { Impulsionamento } \\
\text { de engajamento } \\
\text { no Instagram, } \\
\text { Twitter e } \\
\text { Youtube, }\end{array}$ & 2020 & $\begin{array}{l}\text { Não } \\
\text { identificada. }\end{array}$ & $\begin{array}{l}\text { Acesso às mídias sociais } \\
\text { mediante sincronização de } \\
\text { contas. }\end{array}$ \\
\hline 33 & 1Everve & $\begin{array}{l}\text { Impulsionamento } \\
\text { de engajamento } \\
\text { no Instagram, } \\
\text { Twitter, Youtube, } \\
\text { TikTok, Telegram } \\
\text { e Vkontakte }\end{array}$ & 2019 & Sofia (Bulgária) & $\begin{array}{l}\text { Acesso às mídias sociais } \\
\text { mediante sincronização de } \\
\text { contas em uma extensão } \\
\text { do Go ogle Chrome. } \\
\text { Comissão também mediante } \\
\text { sistema de afiliação de novos } \\
\text { membros }\end{array}$ \\
\hline 34 & 1JobBoy & $\begin{array}{l}\text { Impulsionamento } \\
\text { de engajamento } \\
\text { no Facebook, } \\
\text { Twitter e } \\
\text { Google+) }\end{array}$ & 2010 & $\begin{array}{l}\text { Los Angeles } \\
\text { (Estados } \\
\text { Unidos) }\end{array}$ & \\
\hline 35 & WorkGenius & $\begin{array}{l}\text { Microsserviços } \\
\text { de freelancing }\end{array}$ & 2011 & $\begin{array}{l}\text { New York } \\
\text { (Estados } \\
\text { Unidos) }\end{array}$ & $\begin{array}{l}\text { Plataforma antes nomeada } \\
\text { Mylittlejob }\end{array}$ \\
\hline 36 & Fiverr Brasil & $\begin{array}{l}\text { Microsserviços } \\
\text { de freelancing }\end{array}$ & 2016 & $\begin{array}{l}\text { São Paulo } \\
\text { (Brasil) }\end{array}$ & $\begin{array}{l}\text { Unidade Brasileira da Fiverr } \\
\text { International (criada em Tel } \\
\text { Aviv, Israel) }\end{array}$ \\
\hline 37 & Vintepila & $\begin{array}{l}\text { Microsserviços } \\
\text { de freelancing }\end{array}$ & 2017 & Curitiba (Brasil) & \\
\hline 38 & Vinteconto & $\begin{array}{l}\text { Microsserviços } \\
\text { de freelancing }\end{array}$ & 2015 & $\begin{array}{l}\text { Rio de Janeiro } \\
\text { (Brasil) }\end{array}$ & $\begin{array}{l}\text { Empresa possui operação } \\
\text { também em Kettering, na } \\
\text { Inglaterra }\end{array}$ \\
\hline
\end{tabular}


Continuação Quadro 1...

\begin{tabular}{|c|c|c|c|c|c|}
\hline 39 & SEOClercks & $\begin{array}{l}\text { Microsserviços } \\
\text { de freelancing }\end{array}$ & 2011 & $\begin{array}{c}\text { Hendersonville } \\
\text { (Estados } \\
\text { Unidos) }\end{array}$ & \\
\hline 40 & CrowdTest & $\begin{array}{l}\text { Testes de } \\
\text { usabilidade } \\
\text { remota }\end{array}$ & 2011 & $\begin{array}{l}\text { Belo Horizonte } \\
\text { (Brasil) }\end{array}$ & $\begin{array}{l}\text { Plataforma sob propriedade } \\
\text { da Base2 Tecnologia, } \\
\text { fundada em } 2005\end{array}$ \\
\hline 41 & Testbirds & $\begin{array}{l}\text { Testes de } \\
\text { usabilidade } \\
\text { remota }\end{array}$ & 2011 & $\begin{array}{l}\text { Munique } \\
\text { (Alemanha) }\end{array}$ & \\
\hline 42 & UserTesting & $\begin{array}{l}\text { Testes de } \\
\text { usabilidade } \\
\text { remota }\end{array}$ & 2007 & $\begin{array}{l}\text { San Francisco } \\
\text { (Estados } \\
\text { Unidos) }\end{array}$ & \\
\hline 43 & UserFeel & $\begin{array}{l}\text { Testes de } \\
\text { usabilidade } \\
\text { remota }\end{array}$ & 2010 & Atenas (Grécia) & \\
\hline 44 & uTest & $\begin{array}{l}\text { Testes de } \\
\text { usabilidade } \\
\text { remota }\end{array}$ & 2007 & $\begin{array}{l}\text { Framingham } \\
\text { (Estados } \\
\text { Unidos) }\end{array}$ & \\
\hline 45 & TesterWork & $\begin{array}{l}\text { Testes de } \\
\text { usabilidade } \\
\text { remota }\end{array}$ & 2015 & $\begin{array}{l}\text { Londres } \\
\text { (Inglaterra) }\end{array}$ & \\
\hline 46 & UsabilityHub & $\begin{array}{l}\text { Testes de } \\
\text { usabilidade } \\
\text { remota }\end{array}$ & 2008 & $\begin{array}{l}\text { Melbourne } \\
\text { (Austrália) }\end{array}$ & $\begin{array}{l}\text { Para fazer os testes, os } \\
\text { microtrabalhadores são } \\
\text { direcionados para uma } \\
\text { plataforma intitulada } \\
\text { UserCrowd }\end{array}$ \\
\hline 47 & UserBrain & $\begin{array}{l}\text { Testes de } \\
\text { usabilidade } \\
\text { remota }\end{array}$ & 2014 & Graz (Áustria) & \\
\hline 48 & UserLytics & $\begin{array}{l}\text { Testes de } \\
\text { usabilidade } \\
\text { remota }\end{array}$ & 2009 & $\begin{array}{c}\text { San Francisco } \\
\text { (Estados } \\
\text { Unidos) } \\
\end{array}$ & \\
\hline 49 & Enroll & $\begin{array}{l}\text { Testes de } \\
\text { usabilidade } \\
\text { remota }\end{array}$ & 2018 & $\begin{array}{l}\text { Campbell } \\
\text { (Estados } \\
\text { Unidos) }\end{array}$ & \\
\hline 50 & Ferpection & $\begin{array}{l}\text { Testes de } \\
\text { usabilidade } \\
\text { remota }\end{array}$ & 2014 & Paris (França) & \\
\hline 51 & 1TimeBucks & $\begin{array}{l}\text { Testes de } \\
\text { usabilidade } \\
\text { remota / Pesquisas } \\
\text { / Geração } \\
\text { de tráfego e } \\
\text { engajamento em } \\
\text { sites, jogos e redes } \\
\text { sociais (nnstagram } \\
\text { e TikTok) }\end{array}$ & 2017 & $\begin{array}{l}\text { Sydney } \\
\text { (Austrália) }\end{array}$ & $\begin{array}{l}\text { Empresa faz parte do grupo } \\
\text { Australian Clearing, fundado } \\
\text { em } 2000\end{array}$ \\
\hline
\end{tabular}


Continuação Quadro 1...

\begin{tabular}{|c|c|c|c|c|c|}
\hline 52 & ClipClaps & $\begin{array}{l}\text { Testes de } \\
\text { usabilidade } \\
\text { remota / } \\
\text { Geração de } \\
\text { tráfego via } \\
\text { streaming }\end{array}$ & 2019 & $\begin{array}{l}\text { Seattle (Estados } \\
\text { Unidos) }\end{array}$ & $\begin{array}{l}\text { Empresa controlada pelo } \\
\text { grupo Grand Channel } \\
\text { Entertain me nt. Os } \\
\text { trabalhadores são pagos para } \\
\text { jogarem jogos e assistirem à } \\
\text { vídeos na plataforma. Em } \\
\text { troca, ganham clapcoins, } \\
\text { que podem ser trocadas } \\
\text { por dinheiro e resgatadas } \\
\text { via Paypal. }\end{array}$ \\
\hline 53 & Cashzine & $\begin{array}{l}\text { Testes de } \\
\text { usabilidade } \\
\text { remota/ Geração } \\
\text { de tráfego via } \\
\text { leitura de textos }\end{array}$ & 2018 & $\begin{array}{l}\text { Kuala Lampur } \\
\text { (Malásia) }\end{array}$ & $\begin{array}{l}\text { Trabalhadores são pagos } \\
\text { para geração de tráfego via } \\
\text { eitura de notícias indicadas } \\
\text { pela plataforma. A versão } \\
\text { em português chegou ao } \\
\text { Brasil em } 2020 \text {. }\end{array}$ \\
\hline 54 & Buzzbreak & $\begin{array}{l}\text { Testes de } \\
\text { usabilidade } \\
\text { remota/ Geração } \\
\text { de tráfego via } \\
\text { leitura de textos }\end{array}$ & 2019 & $\begin{array}{l}\text { Seattle (Estados } \\
\text { Unidos) }\end{array}$ & $\begin{array}{l}\text { Geração de tráfego via } \\
\text { streaming ou leitura de } \\
\text { notícias. Em operação no } \\
\text { Brasil desde o segundo } \\
\text { semestre de } 2019 \text {. }\end{array}$ \\
\hline
\end{tabular}

${ }^{1}$ Organizações categorizadas por Casilli et al. (2019) como plataformas de microtrabalho profundo (Plateformes de micro-travail profond), na qual as tarefas são organizadas por diferentes camadas. A primeira camada consiste em uma plataforma para anúncios das tarefas disponíveis. Após demonstrar interesse e ser aceito para uma tarefa ou projeto específico, o trabalhador é direcionado para uma segunda plataforma, em que é realizada a contratação. Por vezes, as tarefas são realizadas nesta segunda camada, porém em outros casos o trabalhador é novamente direcionado para uma terceira plataforma, também terceirizada para serviços específicos (como é o caso, por exemplo, da UHRS da Microsoft, da RaterHub da Google e TryRating, da Apple). 
